\title{
Hearing Care Providers' Perspectives on the Utility of Datalogging Information
}

DOI:

10.1044/2020_AJA-19-00089

\section{Document Version}

Accepted author manuscript

Link to publication record in Manchester Research Explorer

\section{Citation for published version (APA):}

Saunders, G. H., Bott, A., \& Tietz, L. H. B. (2020). Hearing Care Providers' Perspectives on the Utility of Datalogging Information. American journal of audiology. https://doi.org/10.1044/2020_AJA-19-00089

\section{Published in:}

American journal of audiology

\section{Citing this paper}

Please note that where the full-text provided on Manchester Research Explorer is the Author Accepted Manuscript or Proof version this may differ from the final Published version. If citing, it is advised that you check and use the publisher's definitive version.

\section{General rights}

Copyright and moral rights for the publications made accessible in the Research Explorer are retained by the authors and/or other copyright owners and it is a condition of accessing publications that users recognise and abide by the legal requirements associated with these rights.

\section{Takedown policy}

If you believe that this document breaches copyright please refer to the University of Manchester's Takedown Procedures [http://man.ac.uk/04Y6Bo] or contact uml.scholarlycommunications@manchester.ac.uk providing relevant details, so we can investigate your claim.

\section{OPEN ACCESS}




\section{Title page}

2 Title: Hearing care providers' perspectives on the utility of datalogging information

3 Authors: Gabrielle H. Saunders, Anthea Bott, Lukas HB Tietz

4 Affiliation: Eriksholm Research Centre, Snekkersten, Denmark

5

6 Key words: hearing aids, datalogging, mixed-methods

7

8 


\section{Abstract}

Purpose: To learn how (a) datalogging information is being used in clinical practice by hearing care professionals (HCPs) in the US, and (b) HCPs' opinions about how information collected through the hearing aids could be broadened in clinical application.

Methods: A mixed methods approach was undertaken consisting of an online quantitative survey and qualitative structured telephone interviews. Survey data were analyzed using descriptives and chi-squared analyses. The interview data were transcribed and analyzed using inductive content analysis.

Results. In total, 154 HCPs completed the survey, of whom 10 also completed an interview. Survey data showed that most HCPs use datalogging for conventional applications, such as counseling and fine tuning during a hearing aid trial. Interview data highlighted four additional desirable datalogging features: (1) data about the sound environment; (2) details about operational aspects of hearing aid use; (3) data about use and non-use; and (4) automated diagnosis of a hearing aid malfunction. HCPs also envisaged using datalogging in novel ways, such as for demonstrating hearing aid value and supporting decision-making.

Conclusions. Today, datalogging is primarily used as a tool for counseling clients about hours and patterns of hearing aid use, and for troubleshooting and fine tuning. However, HCPs suggested novel and more ambitious uses of datalogging such as for sending alerts about non-use, for automated diagnosis of a hearing aid malfunction, and for helping the client in their decisionmaking. It remains to be seen whether in the future these will be implemented into clinical practice. 


\section{Introduction.}

Datalogging is the automated recording and storing of data collected about hearing aid and cochlear implant use. It has been around since the 1990's when Mangold, Ringdahl and ErikssonMangold developed a hearing aid with a datalogging feature in order to understand patient usage patterns of a multimemory hearing aid (Mangold et al., 1993, Ringdahl, 1994). In the intervening time, datalogging has become a standard feature in almost all makes and models of hearing devices, and the information being logged is expanding. Standard datalogging records total use time, volume control usage and program usage. Some commercially-available hearing aids and cochlear implants now log parameters additional parameters such as the battery lift, time spent streaming data, sound pressure level input (SPL), listening environment classification, directional microphone settings, and signal-to-noise ratio (SNR). However, due to data storage limitations this information is typically stored cumulatively over time, i.e., average use is computed from an evergrowing data log (Kuvadia \& Camacho, 2017). On the other hand, experimental hearing aids connected via a smartphone to the internet have greater storage capacity, so they can log, on a time-stamped minute-by-minute basis, the SPL, noise floor level, signal modulation parameters, SNR of the listening environment in separate frequency bands, and can make sound environment classifications (Pontoppidan et al., 2018).

For research, datalogging has been used to compare self-reported hearing aid and cochlear implant use with that collected by the hearing devices, both in adults (Gaffney, 2008; Solheim \& Hickson, 2017; Maki-Torkko, Sorri, \& Laukli, 2001; Laplante-Lévesque, Nielsen, Jensen, \& Naylor, 2014) and in children (Gustafson, Ricketts, \& Tharpe, 2017). Datalogging information has also been used to understand the relationship between device use patterns and outcome (Easwar, Sanfilippo, Papsin, \& Gordon, 2018), predictors of device use (Walker et al., 2013; Wiseman \& Warner-Czyz, 2018), and for describing listening environments encountered by device users (Easwar, Sanfilippo, Papsin, \& Gordon, 2016; Cristofari et al., 2017; Humes, Rogers, Main, \& Kinney, 2018; Gaffney, 2008). It has even been proposed that datalogging information combined 
with other sources of clinical and real-world data, can be stored in a data repository and later used for evidence-based public health policy making (Dritsakis et al., 2018, Saunders et al., 2019). In sum, the above studies show that (a) adults, and the parents of children who use hearing device, tend to overestimate device usage - particularly when device use is irregular; (b) more consistent device usage results in better outcomes; (c) device usage is greater among children who are older, have poorer hearing, and who have a mother with a higher level of education, and among adult hearing aid users who have more severe hearing impairment and prior hearing aid experience; (d) device users are exposed to a variety of listening environments, but that adults are poor at classifying the sound environments they are exposed to; and (e) more hearing aid use is associated with exposure to higher sound and noise levels and more diverse sound environments.

Of course, data collected using datalogging should be interpreted with some degree of caution because the data are dependent on each manufacturers' algorithms for data collection, analysis and classification of the sound environment which likely vary in their accuracy. To illustrate, hearing aid usage time is usually computed cumulatively over time by measuring the number of hours that the hearing aid is turned on. Thus, if a client removes their hearing aid but does not open the battery door, the hours of usage logged will be an overestimation of actual use.

While publications clearly describe how datalogging information has been used for research, it is less clear how datalogging information is used in clinical practice. Back in 2007, Mueller discussed three possible ways the data could be used: (i) as a counseling tool on the day of fitting to make patients aware that the clinician has access to information about hearing aid use, (ii) as a counseling tool at the initial follow-up visit to facilitate discussion about overall use, and patterns of use of programs and volume control, and (iii) as a tool to assist with troubleshooting and fine tuning the hearing aids. To date, there appears to be just one published study that has investigated how hearing care providers (HCPs) use datalogging information in clinical practice (McMillan, Durai, \& Searchfield, 2018). One hundred eight audiologists in New Zealand were surveyed. It was found that almost $90 \%$ reported datalogging information to be clinically useful. The information was used 
by almost all survey respondents for counseling (94\%), but many also used it for fine tuning the hearing aids and when working with individuals who were unable to provide accurate self-reports. The information most often looked at was hours of use, program and volume control use, and time spent in different listening environments. The information was most often accessed and used during the patient's first follow-up visit. The individuals surveyed in this study were all members of the New Zealand Audiology Society, each held a Master of Audiology degree or the equivalent, they were relatively young, with $67 \%$ of respondents being aged $25-45 \mathrm{yr}$., and $48 \%$ had less than ten years of experience practicing audiology. All adults in New Zealand with a permanent hearing loss and who could benefit are, at a minimum, eligible for a government subsidy for hearing aids, and some are eligible for government hearing aid funding scheme that covers the full cost of hearing aids (https://www.enable.co.nz/services/hearing-aid-funding-and-subsidy/).

We were interested in the opinions about datalogging held by a broader range of HCPs, including hearing aid dispensers, hearing instrument specialists and audiologists, who practiced in the US where there is almost no government funding for hearing aids for adults - beyond that provided for Veterans. The aim of the study was to learn (a) how datalogging information is being used in clinical practice in the US and (b) how HCPs think information collected through the hearing aids could be expanded to broaden its clinical application. To this end, we conducted a short survey, followed by telephone interviews with a subset of the sample surveyed.

\section{Methods.}

The study received approval from the Research Ethics Committee of the Capital Region of Denmark.

Participants. All participants were HCPs who were actively fitting amplification in the USA and whose contact information was stored in a database at Oticon USA. Recruitment took place in two stages. In stage 1 , an invitation to complete the survey was sent to $84 \mathrm{HCPs}$. This version of the 
survey included an invitation to participate in a follow-up phone interview. Thirty-one HCPs completed the survey and of these, ten self-selected to participate in a follow-up interview. In stage 2 , the survey was sent to an additional 500 HCPs. This version of a survey did not include an invite for a follow-up interview and differed in terms of 3 items (see below for details). An additional 123 HCPs completed this second survey. The overall survey response rate was $26.4 \%$.

\section{$\underline{\text { Test measures. }}$}

- HCP Survey. A short survey about use of datalogging information was developed and then input regarding content and phrasing was obtained from three audiologists. Changes were made based upon the input, resulting in Version 1 of the survey.

Version 1 of the survey consisted of 9 demographic and job-related items, and 3 items about use of datalogging information. Each of these datalogging items had a single follow-up question (total of 3) contingent upon the initial response.

Version 2 of the survey consisted of the same 9 demographic and job-related items, and the same 3 items about use of datalogging information. However, in this version there were 5 possible follow-up questions contingent upon the initial response. The additional questions were added following input from colleagues.

The surveys were entered into the Qualtrics ${ }^{\mathrm{XM}}$ Survey Software which permits responses to be formatted for a single option response, multiple option responses, and free-text responses, as well as for a contingency pathway. Each of these formats were used in the surveys here. Both surveys can be found in Appendix 1.

- HCP Interview. A structured interview guide was developed to learn about participants' thoughts about use and collection of real-world data from clients and their hearing aids. It consisted open-ended questions with follow-up questions and prompts. See Appendix 2.

Participant payment. Participants did not receive payment for completing the survey. The ten HCPs who took part in the one-on-one phone interview received a $\$ 50$ gift card. 


\section{Procedures}

136 Stage 1. Emails were sent to $84 \mathrm{HCPs}$. The body of the email message comprised an invitation to 137 complete the survey by following the in-message link to the Qualtrics survey page. Beyond 138 collecting email addresses of individuals who self-selected to be contacted for a follow-up 139 interview, no personal health information or identifiable information were collected. Data were 140 collected over a period of eleven days beginning on May $17^{\text {th }}, 2019$.

All HCPs who responded that they were willing participate in a one-on-one structured phone interview and who provided an email address were sent an email inviting them to schedule an interview. Of the 15 who initially volunteered to be interviewed, ten were successfully contacted and interviewed. All but one interview took place via skype for business. One individual happened to be visiting the test site and so was interviewed in person. Interviews took place between July $10^{\text {th }}$ and July $30^{\text {th }}, 2019$ with the first (G.S.) and third author (L.T.) Prior to starting all interviews, we asked permission to record the interview. All agreed to this. Electronic recordings of each interview were stored on a secure password-protected server for transcription.

Stage 2. Emails were sent to an additional $500 \mathrm{HCPs}$. The body of the message was identical to that in stage 1, except that no mention was made of a follow-up interview, and the in-message link 151 took potential participants to Version 2 of the survey. Data were collected over an 8-day period, 152 between July $10^{\text {th }}$ and July $18^{\text {th }}, 2019$.

\section{Analyses.}

155 Survey data were downloaded from the Qualtrics software into an excel spreadsheet, which was 156 then read into IBM SPSS Statistics for analyses. Analyses comprised of descriptive, crosstabs and 157 chi-squared analysis. 
158 Interview data were transcribed and analyzed using inductive content analysis as described by

159 Erlingsson and Brysiewics (2017)., Content analysis was used to analyze the interview data

160 because it is recommended when there is limited research or theory about a phenomenon (Hsieh

161 and Shannon, 2005), which is the case with HCPs perceptions of datalogging. An inductive

162 approach was used as findings were generated from the data, as opposed to being mapped to an

163 existing theory or model (deductive). The analysis was completed by the second author (A.B.), who

164 was not involved in the interviews. She was provided with the aims of the study and the transcripts.

165 As outlined by Erlingsson and Brysiewics (2017), initially, transcripts were read and re-read,

166 ensuring the second author (A.B) was familiar with the data. Notes were written down, identifying

167 the main concepts relevant to this study. Then, relevant text was highlighted and broken into

168 smaller sections, called meaning units. Meaning units were shortened or condensed, whilst

169 ensuring that the core meaning was retained. Condensed meaning units were assigned a code or

170 label and similar codes were grouped together, creating categories. Finally, two or more categories

171 that were rich in latent meaning, referring to why or how, were grouped together to create themes.

172 The final report, produced by the second author (A.B), was reviewed and agreed to by the first

173 author (G.S) who had conducted all interviews. Thus, the qualitative findings were confirmed by the

174 first and second author through two separate means.

176 Results.

177 1. Survey Data

178 Demographic information. Table 1 shows demographic information from the survey respondents

179 and interviewees separately. Note, however, that the data from the 10 individuals who were

180 interviewed is included in the survey respondent data. With the exception that there were a greater

181 proportion of males among the interviewees than the survey respondents, the HCPs who were 
interviewed were generally demographically similar to those who completed the surveys, thus their views can be expected to represent those of the larger group.

How often do HCPs use datalogging information? Of the 154 survey respondents, $49.4 \%$ ( $n=76)$ said they looked at datalogging information 'always or usually', $40.9 \%(n=63)$ said they looked at it 'sometimes', $8.4 \%(n=13)$ said 'rarely', and 1.3\% $(n=2)$ reported that they 'never' looked at datalogging information. Table 2 shows the reasons given for not using datalogging by the 78 respondents who responded that they 'sometimes', 'rarely', or 'never' looked at datalogging information. Participants were permitted to choose more than one reason for not using datalogging information - hence there are more than 78 responses to this question.

When datalogging information is unused it is generally because it is not considered to have clinical utility. This is seen both from the closed set responses but also from the free text responses.

Are HCPs interested in receiving additional datalogging information? In general, respondents were interested in the possibility of receiving more detailed data logging information, such as how and when a client adjusts his/her hearing aids, or graphs of minute-by-minute use in different listening environments, as illustrated by the fact that $77.3 \%(n=119)$ participants responded 'Yes, I am interested in this'. On the other hand, $16.9 \%(n=26)$ responded 'unsure', 3.9\% $(n=6)$ responded 'Yes, but it is not practical for me', and 1.9\% $(n=3)$ responded 'no'. When these latter 34 participants were asked to further explain their thinking, most $(n=29)$ responded 'I am not sure how I would use the data in my clinical care', four cited technical concerns (unsure how to access the data, additional data might decrease battery life), four considered that currently available data is and should be sufficient for provision of clinical care, and one said (s)he has no time to add this to clinical care.

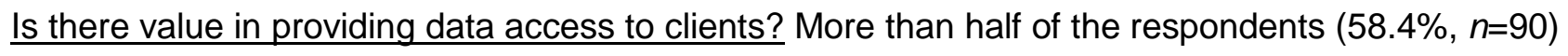
said they would be interested in providing their clients with an app that allowed the client to see detailed information about his/her own hearing aid use, 29.2\% $(n=45)$ were unsure about this, $10.4 \%(n=16)$ said they were not interested in this, and $1.9 \%(n=3)$ felt it would be impractical. 
Reasons given by those who said they were not interested are shown in Table 3. Once again, participants could give more than one reason, and once again the primary reasons could be classified as the information having little or no clinical utility.

When and how is datalogging used? The 123 participants who responded to version 2 of the survey answered two additional questions: 'When do you look at the datalogging information?' and 'How do you use datalogging information in your clinical process?'. Participants were permitted to choose more than one response, so again there are more than 123 responses to each question. Over three quarters of respondents look at the datalogging information during a follow-up appointment (88.6\%, $n=109), 17.1 \%(n=21)$ look at it 'on a regular basis', $4.1 \%(n=5)$ look at it prior to a follow-up appointment and $4.9 \%(n=6)$ look at it at other times, such as when a problem arises, at each visit and if a client requests the information.

Table 4 shows how participants use datalogging information in clinical practice. The fact that participants use datalogging information in multiple ways shows that it can have many applications - in particular, for monitoring/confirming hearing aid use, for counseling, and as a basis for making hearing aid adjustments.

Chi-square analyses were used to determine whether there were any relationships between demographic variables (age, education level, years in practice, daily client load) and interest in use of datalogging information, interest in additional data and in providing client with access to data. There were no statistically significant relationships indicating that, among the population here, demographic variables are not determinants of use of datalogging.

\section{Interviews}

Responses from the interviewees are presented below in three sections, reflecting the questions asked in the interview: current perception and use of datalogging, future datalogging features, and future applications of datalogging. After each quote we provide information about the individual 
233 from whom the quote was taken in terms of a coded identifier, the gender and the number of years

234 they have practiced audiology.

235 Current perception and use of datalogging. Two themes emerged that represented the HCPs 236 current use and attitude toward datalogging. An overview of the themes, categories and codes 237 relating to current perception and use of datalogging is summarized in Table 5.

(i) A positive attitude toward capabilities 'The more information you can give us, the

better we can do our job.' (HCP 5, Male, 10+) (Coded identifier, gender, number of years'

\section{experience working as an $\mathrm{HCP}$ ).}

Broadly, HCPs had a positive attitude toward datalogging. They reported datalogging was 'helpful' and 'useful' to them and discussed how datalogging could be expanded to enhance

Further reinforcing HCPs' positive attitude toward prospective datalogging capabilities were the comments made by three HCPs who acknowledged minimal current use of datalogging. All three were interested in learning how other HCPs use datalogging and exploring how they could use it in their clinic. For example, one HCP stated

'I look forward to using it. I look forward to kind of experimenting with it and see how much I use it and when it will be the most useful.' (HCP 8, Female, 10+).

\section{(ii) Application is limited to specific clients and purposes}

Although HCPs had a positive attitude toward datalogging in clinical care, many highlighted currently only using it to address the needs to specific clients and/or for a specific purpose. For example, one HCP explained'I will be honest. I certainly, I don't think it is something that I would use for the majority of patients.' (HCP 8, Female, 10+). There was agreement among HCPs that 'checking' datalogging was most helpful for clients who were having difficulties with their hearing aid. HCPs often used datalogging to check clients hearing aid use, as well as use 
of volume and programs. HCPs reported using this information for counselling or fine tuning the hearing aid, particularly during a hearing aid trial. For example, one HCP explained '... especially in their trial period and they say they're having trouble adjusting to the sound and I look at datalogging and they've only worn them for two hours a day, that tells me, that I need to counsel a little bit more about the importance of wearing the hearing aids all day every day for the first couple weeks, to let your brain adjust to the sound.'

' (HCP 1, Female, $\underline{0-1)}$.

Future uses of datalogging information. Four desirable features for datalogging were described by HCPs: (1) data about the sound environment; (2) details about operational aspects of hearing aid use; (3) data about use and non-use; (4) automated diagnosis of a hearing aid malfunction. There is no table for this section because there are no latent themes in the responses.

\section{(i) Data about the sound environment 'I think the environmental data would be the}

\section{biggest one that I would like to see in there.' (HCP 2, Male, 6-10)}

HCPs wanted more information on the sound environment relevant to client's lifestyle. For example, HCPs were interested in knowing how often clients were in different types of sound environment, such as noisy versus quiet. They wanted this information to be presented via a classification system or by having access to the signal-to-noise ratio. Several HCPs saw value in clients being able to take an auditory 'snapshot' or a sound recording of a challenging sound environment. For example, one HCP explained:

If there was a way of them marking, the patient to somehow subjectively say 'okay I need to; this is the place I'm having trouble' and so we, you know, take a snippet of that situation, and then we can sit down and analyse what was going on in that information, in that sample.' (HCP 5, Male, 10+)

The overall benefit and use of more detailed information on the sound environment was considered helpful for aspects of fine tuning, counselling and troubleshooting, and for building a 
better understanding of the client's needs. HCPs also considered this information helpful for clients who were 'vague' or had difficulty recalling their sound environments.

\section{(ii) Details about operational aspects of hearing aid use}

HCPs wanted more detail about how their clients operate their hearing aids. They were interested in being able to monitor clients' use of each program, use of streaming, volume control changes and how they connected the hearing aids to their phone. HCPs were also interested in having data that would provide insight as to whether clients were incorrectly operating their hearing aids. They said they would use this type of information for counselling.

In particular, HCPs were interested in accessing information about battery use and life. They wanted this information for troubleshooting reports of battery life issues. Several HCPs explained that clients often unknowingly have streaming turned on, which considerably reduces the life of the battery.

'... people might [sic] realize, may not think they're streaming, and they actually are streaming. They're turning on like the microphone or the end on the on the phone the phone mic or something like that and then say 'hey you don't realize it but your phone is actually connected streaming Bluetooth for, you know, six hours through the day.' $\mathrm{HCP}_{2}$ Male, 6-10)

\section{(iii) Data about hearing aid use and non-use}

HCPs reported that obtaining information about hearing aid use and non-use would enable them to be proactive in their client care. Being proactive was considered important for preventing client frustration, impressing clients, and minimizing hearing aid returns and/or nonuse- - HCPs explained that having earlier knowledge that an individual is not using their hearing aids would help them problem solve with clients. They said that it would be valuable to have this kind of information throughout the lifetime of the hearing aid, both during a hearing aid trial period and beyond, as illustrated by the following two statements made by different HCPs: 
'Great example, just this past week: I loaned out some demos to a guy and he came back and told me he only wore them one day, because he was afraid to wear them. He thought he might lose them or damage them. And if I found out, you know, two days later, that he hadn't been wearing them, I could have proactively called him and asked, you know, is something wrong? Why are you not wearing them?' (HCP 4, Male, 10+)

'Certainly, would want to know if usage changes for some reason or the other. Just last week, a patient said she had stopped using whatever hearing instruments about a month ago and then didn't make an appointment to come in for a month. That would be very good information.' (HCP 7, Female, 10+)

\section{(iv) Automated diagnosis of a hearing aid malfunction}

Although not a specific question in the structured interview guide, several HCPs brought up the considerable value of an automated diagnosis of a hearing aid malfunction, i.e. a hearing aid that could self-test for functional problems. Two HCPs described this feature as being like a 'warning light in your car' prompting you that your fuel is low. HCPs reported that having a warning of a hearing aid malfunction would help reduce clients' frustration. They noted that often clients are unaware of a malfunctioning hearing aid and thus do not seek help in a timely manner. They suggested that being sent an alert about a malfunctioning receiver or microphone would be highly positive and advantageous and would allow them to provide proactive care. As one HCP explained:

'That's going to really impress any patient, that if you call them and tell them you know we've discovered that your microphone is malfunctioning, we need you to come in so that we can take care of that. That's going to blow them away in terms of customer service.' 
Similarly, some HCPs also saw value in being notified if a hearing aid were lost and also saw value in then being able to locate where the hearing aid was last used.

'If a hearing aid was lost, if it separates from its partner, I would love that [notification].'

\section{(HCP 10, Female, 10+)}

Associated with this, several HCPs reflected on the issue of client privacy if they were to be able to more closely monitor clients hearing aid use (or non-use). HCPs commonly resolved this concern by acknowledging that clients should be able to 'opt-in' or 'opt-out' of datalogging.

Future applications of datalogging. HCPs discussed aspects of applications of datalogging: (i) different levels of datalogging over time, (ii) the dubious value of client-initiated alerts, and (iii) demonstrating hearing aid value and supporting decision-making. An overview of the themes, categories and codes relating to HCPs perspectives toward the future applications of datalogging

\section{is summarized in Table 6.}

\section{(i) Different levels of datalogging over time: 'It makes sense to change it obviously.' $(H C P$}

\section{5, Male, 10+)}

When HCPs discussed specific features and how datalogging could be expanded to assist them in clinical practice, it emerged that there was a difference in what they wanted from datalogging information relevant over time. For example, during a hearing aid trial period, HCPs wanted comprehensive information and reported they would like to access information related to different sound environment, operational aspects of the hearing aid and client's satisfaction, use and non-use. However, once the trial period was over, they were happy for datalogging information to be collected on an ongoing basis, but only wanted to be notified when the data indicated a change in usage or behavior - such as hearing aid malfunction, non-use of the hearing aids, or a change in the sound environment profiles. They also reported that it would be unnecessary to receive alerts about use and behavior changes after the hearing aid trial period was completed. As one HCP summed up: 
'I would probably want more kind of comprehensive, more specific information during the trial period, because that would really be used as a tool to give me information on how I can program the hearing aids or, you know, fine tune the hearing aids to give that client more benefit. Versus if it"s an older device I would really just want to know, are they still using it?' (HCP 1, Female, 0-1)

\section{(ii) The dubious value of client-initiated real time alerts 'Obviously the chance of it being} abused is quite high.' (HCP 5, Male, 10+)

HCPs were asked to reflect on the value of real-time client-initiated alerts, meaning the ability for the client to directly alert the HCP about a concern or problem. While most HCPs saw value in receiving an automated alert in specific situations - such as hearing aid malfunction or hearing aid non-use, they were dubious about having clients initiate these alerts. Several HCPs were concerned that some clients would 'abuse' this feature and that they would therefore be 'bombarded' with client-initiated alerts. Other HCPs said that a client-initiated real time alert was not any different to the current situation in which a client sends an email or phones when an issue arises.

Furthermore, HCPs were generally against receiving information about a problem or concern directly in an alert. Instead, they wanted the detailed alert to go into the hearing aid software, with a notification being sent via email or SMS that there was alert to be investigated. As one HCP explained:

'You know, a flash of a light and you have a notification. Then you got to log in to software to find out what the notification's about.' (HCP 4, Male, 10+)

This approach was preferred by HCPs because it allowed them to control when they accessed the alerts. 
HCPs discussed using datalogging information to demonstrate the value of hearing aids to their clients. For example, HCPs reported that having datalogging information that could demonstrate the 'amount of work' a hearing aid is doing in different situations, could help a client see value in

\section{Discussion}

The aim of this study was first to learn how datalogging information is being used in clinical practice in the US by having practicing HCPs complete a short survey, and second, to dig deeper 
405

406

into this by interviewing a subset of survey respondents to find out how they think datalogging and other data collected through real world use of hearing aids could be used in clinical practice.

Survey findings showed that most HCPs currently use datalogging, and that it is most commonly used during follow-up appointments. When it is not used, it is because the HCPs considered the information provided has little or no clinical utility, is not actionable, or if a client has no problems, no action is needed. Interview findings were consistent with survey findings in that most HCPs had a positive attitude toward datalogging, wanted more features from it and wanted more comprehensive information during the hearing aid trial compared to on an ongoing basis.

Furthermore, while the surveys and interviews showed that HCPs used datalogging information for conventional applications such as monitoring hearing aid use, counselling, and fine tuning the hearing aids, the HCPs who were interviewed identified novel uses for datalogging such as for tracking changes in hearing aid use, sending alerts about non-use, for automated diagnosis of a hearing aid malfunction, and for helping the client in their decision making. Both the survey and interviews indicated that HCPs were reluctant to give clients access to data and control of alerting capabilities. They reported that clients would not be interested and/or capable of understanding data logged information, and that some clients would 'abuse' the option for initiating alerts. On the other hand, HCPs were open to receiving automated alerts about hearing aid malfunction or nonuse, as long as they had an element of control over these alters by having details about the problem stored in hearing aid software, rather than being provided in the alert itself. In this way they could look at the alert when they chose to do so. Overall then, the findings from our survey and interviews are in line with the findings of McMillan et al. (2018), illustrating that datalogging is used and considered valuable to HCPs in clinical practice.

HCPs who took part in the interviews discussed that they would like to expand some datalogging features so that it can be have benefits that extend beyond counselling and fine-tuning hearing aids. They wanted more detailed information on clients use of programs, use of volume control and their sound environment. Once again, this finding is consistent with that reported by McMillan et al. 
431 (2018) who reported that program use, use of volume control and a sound 'snapshot' were useful 432 datalogging information for HCPs to have during a hearing aid trial. In the present study, HCPs 433 also mentioned the potential value of an objective sound 'snapshot', explaining this would be 434 helpful for clients who have difficulty objectively recalling details. They also suggested that this 435 information could be used to help clients understand which hearing aid level of technology is most 436 suitable for them.

437 While the study design of McMillan et al. (2018) did not observe HCPs use of detailed datalogging 438 information after the hearing aid trial period - because the observation period was limited to 439 hearing aid fitting and follow-up appointments only - information from the present study suggests 440 that HCPs want different information during a hearing aid trial as compared to later on. Although 441 not stated aloud, this might be because they are willing to give more intensive and extensive support during the trial period than once a hearing aid has been purchased. On the other hand, the HCPs interviewed did not intend to stop monitoring datalogging information entirely, but they were more selective in the information they wanted to receive. First, HCPs said that automated alerts about a hearing aid malfunction and hearing aid non-use would be valuable. They explained that months can pass before they become aware of cessation or malfunction because many clients may not realize that their hearing aid is not performing optimally or may only tell the HCP to nonuse during a scheduled appointment. Thus, having real-time alerts in these specific instances would allow HCPs to proactively contact clients, which HCPs perceived as demonstrating a high 450 level of customer support and demonstrating their value to their clients. Second, HCPs said that 451 having information relating to use of streaming and battery consumption would be highly beneficial 452 because it is not uncommon for clients to raise concerns over 'short' battery life. The HCPs 453 hypothesized this is because some clients unknowingly have streaming capabilities enabled. In such cases the HCPs said they would use the datalogging information to show the client that they were in streaming mode more often than they knew and could show them that streaming directly 456 impacted battery life. 
457 While HCPs wanted a real-time alert relating to hearing aid non-use or malfunction there were few 458 other instances in which an alert was desired, and they were very wary of permitting clients to 459 generate real-time alerts. In general, they commonly said that they preferred to schedule an 460 appointment with the client once they were made aware of an issue rather than to use a remote 461 care app to address the problem. The reluctance to use teleaudiology has been reported 462 elsewhere (Singh, Pichora-Fuller, Malkowski, Boretzki, \& Launer, 2014), although a recent 463 systematic review suggests attitudes are changing (Ravi, Gunjawate, Yerraguntla, \& Driscoll, 464 2018).

465 While using a mixed-methods approach allowed for a better understanding of HCPs current use 466 and future wants from datalogging than either purely quantitative or qualitative methods used on 467 their own, a limitation of this study was the use of convenience sampling for both surveys and 468 interviews and therefore self-selection bias may be present. More specifically, it is likely that the individuals who participated in the study had either strongly positive or strongly negative views about data logging that they wanted to share with the investigators. However, it is not possible to ascertain this from the study.

$\underline{\text { Conclusion }}$

474 In conclusion, it seems that Mueller's 2007 suggestions that datalogging be used as a tool for 475 counseling clients about hours and patterns of hearing aid use, and for troubleshooting and fine 476 tuning, has come into practice. However, today's HCPs can envisage novel and more ambitious 477 uses of datalogging such as for tracking changes in hearing aid use, sending alerts about non-use, 478 for automated diagnosis of a hearing aid malfunction, and for helping the client in their decision479 making. It remains to be seen whether the combination of technology and clinical interest will see 480 these implemented into clinical practice in a few years' time. 
Acknowledgments. We thank Don Schum for his assistance with recruiting study participants and valuable input on the survey content.

\section{References}

Cristofari, E., Cuda, D., Martini, A., Forli, F., Zanetti, D., Di Lisi, D., ... Malerba, P. (2018). A Multicenter Clinical Evaluation of Data Logging in Cochlear Implant Recipients Using Automated Scene Classification Technologies. Audiology and Neurotology, 22(4-5), 226-235.

Dritsakis, G., Bamiou, D., Kikidis, D., Bibas, A., Koloutsou, N., Murdin, L., ... Pontoppidan, N. (2018). Clinical validation of a public health policy-making platform for hearing loss (EVOTION): Protocol for a big data study. BMJ Open, 8(2), e020978. https://doi.org/10.1136/bmjopen-2017$\underline{020978}$

Easwar, V., Sanfilippo, J., Papsin, B., \& Gordon, K. (2016). Factors Affecting Daily Cochlear Implant Use in Children: Datalogging Evidence. Journal of the American Academy of Audiology, 27(10), 824-838. https://doi.org/10.3766/jaaa.15138

Easwar, V., Sanfilippo, J., Papsin, B., \& Gordon, K. (2018) Impact of Consistency in Daily Device Use on Speech Perception Abilities in Children with Cochlear Implants: Datalogging Evidence Journal of the American Academy of Audiology, 29(9), 868-869. https://doi.org/10.3766/jaaa.17051

Erlingsson, C., \& Brysiewicz, P. (2017). A hands-on guide to doing content analysis. African Journal of Emergency Medicine, 7(3), 93-99. https://doi.org/10.1016/j.afjem.2017.08.001

\section{Hsieh, H.-F., \& Shannon, S. E. (2005). Three Approaches to Qualitative Content} Analysis. Qualitative Health Research, 15(9), 1277-1288.

\section{https://doi.org/10.1177/1049732305276687}


505 Gaffney, P. (2008) Reported hearing aid use versus datalogging in a VA population. Hearing $506 \quad$ Review, 15(6), 42, 44, 46-47.

507 Gustafson, S., Ricketts, T., \& Tharpe, A. (2017). Hearing Technology Use and Management in 508 School-Age Children: Reports from Data Logs, Parents, and Teachers. Journal of the American 509 Academy of Audiology, 28(10), 883-892. https://doi.org/10.3766/jaaa.16042

510 Humes, L., Rogers, S., Main, A., \& Kinney, D. (2018). The Acoustic Environments in Which Older 511 Adults Wear Their Hearing Aids: Insights From Datalogging Sound Environment $512 \quad$ Classification. American Journal of Audiology, 27(4), 594-603. $513 \quad$ https://doi.org/10.1044/2018 AJA-18-0061

514 Kuvadia, S., \& Camacho, L. (2017). Data logging - Hearing aid behavior in the real world. 515 AudiologyOnline, Article 20258. Retrieved from www.audiologyonline.com 516 Laplante-Lévesque, A., Nielsen, C., Jensen, L., \& Naylor, G. (2014). Patterns of hearing aid usage 517 predict hearing aid use amount (data logged and self-reported) and overreport. Journal of the 518 American Academy of Audiology, 25(2), 187-198. https://doi.org/10.3766/jaaa.25.2.7

519 Maki-Torkko, E., Sorri, M., \& Laukli, E. (2001). Objective assessment of hearing aid 520 use. Scandinavian Audiology, 30, 81-82. https://doi.org.10.1080/010503901300007146

521 Mangold S, Ringdahl A, \& Eriksson-Mangold M. (1993) Datalogging as a tool for measuring the 522 benefit of multiprogrammable hearing instruments. In: Beilin J, Jensen GR, eds. Recent 523 developments in hearing instrument technology. (443-452) (15th Danavox Symp.). Kolding,. $524 \quad 443-452$.

525 McCreery, R. (2013). Data Logging and Hearing Aid Use: Focus on the Forest, Not the Trees. The 526 Hearing Journal, 66(12), 18-19. https://doi.org/10.1097/01.HJ.0000441059.24409.d7 
McMillan, A., Durai, M., \& Searchfield, G. D. (2018). A survey and clinical evaluation of hearing aid data-logging: a valued but underutilized hearing aid fitting tool. Speech, Language and Hearing, 21(3), 162-171. https://doi.org/10.1080/2050571X.2017.1339942

Mueller, H. G. (2007). Data logging: It's popular, but how can this feature be used to help patients? The Hearing Journal, 60(10), 19-26.

\section{https://doi.org/10.1097/01.HJ.0000295442.16133.d7}

Pontoppidan, N. H., Li, X., Bramsløw, L., Johansen, B., Nielsen, C., Hafez, A., \& Petersen, M. K. (2018). Data-driven hearing care with time-stamped data-logging. Proceedings of the International Symposium on Auditory and Audiological Research (ISAAR), Vol. 6: Adaptive Processes in hearing. August 2017, Nyborg, Denmark. S. Santurette, T. Dau, J.C.-Dalsgaard, L. Tranebjærg, T. Andersen, and T. Poulsen (Eds). The Danavox Jubilee Foundation, 2017.

Ravi, R., Gunjawate, D. R., Yerraguntla, K., \& Driscoll, C. (2018). Knowledge and Perceptions of Teleaudiology Among Audiologists: A Systematic Review. Journal of Audiology \& Otology, 22(3), 120-127. https://doi.org/10.7874/jao.2017.00353

Ringdahl, A. (1994). Listening strategies and benefits when using a programmable hearing instrument with eight programs. Ear, Nose and Throat Journal, 73(3), 192-196.

Saunders, G. H., Christensen, J. H., Guttenburg, J., Pontopidan, N. H., Smith, A., Spanoudakis, G., \& Bamiou, D. (2019) Application of big data to support evidence-based public health policy decision-making for hearing. Ear and Hearing. Manuscript submitted for publication.

Singh, G., Pichora-Fuller, M. K., Malkowski, M., Boretzki, M., \& Launer, S. (2014). A survey of the attitudes of practitioners toward teleaudiology. International Journal of Audiology, 53(12), 850 860. https://doi.org/10.3109/14992027.2014.921736

Solheim, J., \& Hickson, L. (2017). Hearing aid use in the elderly as measured by datalogging and self-report. International Journal of Audiology, 56(7), 472-479. https://doi.org/10.1080/14992027.2017.1303201 
552 Walker, E. A., McCreery, R. W., Spratford, M. J., Oleson, J. P., Van Buren, J., Bentler, R., ...

553 Moeller, M. (2015). Trends and Predictors of Longitudinal Hearing Aid Use for Children Who $554 \quad$ Are Hard of Hearing. Ear and Hearing, 36 Suppl 1, 38S-47S.

555 https://doi.org/10.1097/AUD.0000000000000208

556 Walker, E., Spratford, M., Moeller, M., Oleson, J., Ou, H., Roush, P., \& Jacobs, S. (2013).

557 Predictors of Hearing Aid Use Time in Children With Mild-to-Severe Hearing Loss. Language,

558 Speech \& Hearing Services in Schools (Online), 44(1), 73-88. https://doi.org/10.1044/0161-

$559 \quad \underline{1461(2012 / 12-0005)}$

560 Wiseman, K. B., \& Warner-Czyz, A. D. (2018). Inconsistent device use in pediatric cochlear implant 561 users: Prevalence and risk factors. Cochlear Implants International, 19(3), 131-141.

$562 \quad$ https://doi.org/10.1080/14670100.2017.1418161 
Table 1. Demographic information from 154 survey respondents and 10 interviewees

\begin{tabular}{|c|c|c|c|c|}
\hline & \multicolumn{2}{|c|}{$\begin{array}{c}\text { Survey } \\
\text { respondents }\end{array}$} & \multicolumn{2}{|c|}{ Interviewees } \\
\hline & $n$ & $\%$ & $n$ & $\%$ \\
\hline $\begin{array}{r}20-30 \\
31-40 \\
41-50 \\
51-60 \\
61+\end{array}$ & $\begin{array}{c}9 \\
37 \\
30 \\
39 \\
39\end{array}$ & $\begin{array}{l}5.8 \\
24.0 \\
19.5 \\
25.3 \\
25.3\end{array}$ & $\begin{array}{l}2 \\
2 \\
2 \\
1 \\
3\end{array}$ & $\begin{array}{l}20 \\
20 \\
20 \\
10 \\
30\end{array}$ \\
\hline $\begin{array}{r}\text { Female } \\
\text { Male } \\
\text { Diverse } \\
\text { Undisclosed }\end{array}$ & $\begin{array}{c}119 \\
35 \\
0 \\
0\end{array}$ & $\begin{array}{r}77.3 \\
22.7 \\
0.0 \\
0.0\end{array}$ & $\begin{array}{l}5 \\
5 \\
0 \\
0\end{array}$ & $\begin{array}{c}50 \\
50 \\
0 \\
0\end{array}$ \\
\hline 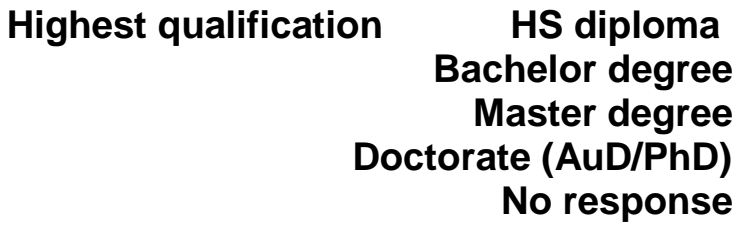 & $\begin{array}{c}9 \\
21 \\
19 \\
104 \\
1\end{array}$ & $\begin{array}{c}5.8 \\
13.6 \\
12.3 \\
67.5 \\
0.6\end{array}$ & $\begin{array}{l}2 \\
1 \\
0 \\
7 \\
0\end{array}$ & $\begin{array}{c}20 \\
10 \\
0 \\
70 \\
0\end{array}$ \\
\hline $\begin{array}{r}0-1 \\
\text { Duration practicing audiology (yr.) } \\
2-5 \\
6-10 \\
>10\end{array}$ & $\begin{array}{c}4 \\
11 \\
18 \\
121\end{array}$ & $\begin{array}{c}2.6 \\
7.1 \\
11.7 \\
78.6\end{array}$ & $\begin{array}{l}2 \\
0 \\
1 \\
7\end{array}$ & $\begin{array}{c}20 \\
0 \\
10 \\
70\end{array}$ \\
\hline Average daily client load (n) & $\begin{array}{c}2 \\
66 \\
86\end{array}$ & $\begin{array}{c}1.3 \\
42.9 \\
55.8\end{array}$ & $\begin{array}{l}0 \\
5 \\
5\end{array}$ & $\begin{array}{c}0 \\
50 \\
50\end{array}$ \\
\hline
\end{tabular}


Table 2. Reasons given for using not datalogging information ( $n=89$ respondents).

\begin{tabular}{rcc}
\hline Response options & \multicolumn{2}{c}{ Respondents } \\
& $\mathbf{n}$ & $\%$ total \\
\hline I do not have the time to add this to my clinical care & 9 & 5.8 \\
I am not sure how to make use of the data in my clinical care & 15 & 9.7 \\
The information I can access is not clinically useful & 29 & 18.8 \\
Other & 36 & 23.4 \\
\hline Free text 'other' responses \\
Unnecessary if patient is doing well/has no complaints/problems & 14 \\
Information is not needed to accomplish clinical care/goals & 9 \\
Forget to use it & 7 \\
Only use it to confirm/determine hearing aid use & 3 \\
Patient can provide the relevant information & 3 \\
\hline
\end{tabular}


Table 3. Reasons given for not being interested in providing data access to clients ( $n=64$ respondents)

\begin{tabular}{|c|c|c|}
\hline \multirow[t]{2}{*}{ Response options } & \multicolumn{2}{|c|}{ Respondents } \\
\hline & $n$ & $\%$ total \\
\hline I would not have the time to add this to my clinical care & 13 & 8.4 \\
\hline $\begin{array}{r}\text { My clinic does not have a good enough internet for me to help } \\
\text { patient with this }\end{array}$ & 1 & 0.6 \\
\hline I do not think my patients would be interested & 35 & 22.7 \\
\hline $\begin{array}{l}\text { I do not think my patients would be able to do this and/or they do } \\
\text { not have the necessary equipment (smart cell phone etc.) }\end{array}$ & 27 & 17.5 \\
\hline I have tried it already and it was problematic & 5 & 3.2 \\
\hline Other & 18 & 11.7 \\
\hline Free text 'other' responses & & \\
\hline More information may cause problems and confusion & 7 & \\
\hline Patients won't see how they benefit from the information & 5 & \\
\hline Will add clinical burden (training in use, dealing with issues raised) & 2 & \\
\hline Does not change behavior & 1 & \\
\hline Adds patient burden with little gain & 1 & \\
\hline No reason provided & 2 & \\
\hline
\end{tabular}


Table 4. Clinical uses of datalogging information ( $n=118$ respondents)

\begin{tabular}{rrcc}
\hline Response options & \multicolumn{2}{c}{ Respondents } \\
& & n & \% total \\
\hline & To monitor hearing aid usage & 115 & 74.7 \\
& To discuss information with the patient & 95 & 61.7 \\
To adjust hearing aid settings & 71 & 46.1 \\
Confirm patient reported usage & 95 & 61.7 \\
& Decide if patient needs a follow-up visit & 22 & 14.3 \\
Other & 6 & 3.9 \\
\hline Free text 'other' responses & \\
To assess appropriate level of technology for patient & 1 & \\
To learn about hearing aid management (open battery door) & 1 & \\
To learn about hearing aid use patterns & 2 & \\
To counsel patient & 2 \\
\hline
\end{tabular}


Table 5 Summary of themes, categories and codes relating to current perception and use of datalogging

\begin{tabular}{lll}
\hline Themes & Categories & Codes \\
\hline $\begin{array}{l}\text { Positive attitude toward future } \\
\text { capabilities }\end{array}$ & Positive reaction & $\begin{array}{l}\text { Helpful } \\
\text { Useful } \\
\text { Wanting more }\end{array}$ \\
& Open to learning & $\begin{array}{l}\text { Limited use } \\
\text { Unsure of application } \\
\text { Interested }\end{array}$ \\
& & Difficult clients \\
$\begin{array}{l}\text { Application is limited to specific } \\
\text { clients and purpose }\end{array}$ & $\begin{array}{l}\text { Use with challenging } \\
\text { clients }\end{array}$ & $\begin{array}{l}\text { Clients with problems } \\
\text { Clients that cannot recall } \\
\text { details }\end{array}$ \\
& & $\begin{array}{l}\text { Hearing aid use } \\
\text { Program use } \\
\text { Volume use }\end{array}$ \\
& & $\begin{array}{l}\text { Counseling } \\
\text { Important during trial }\end{array}$ \\
& & $\begin{array}{l}\text { Client's lifestyle } \\
\text { Listening environment }\end{array}$ \\
\hline
\end{tabular}


Table 6 Summary of themes, categories and codes relating to perception toward future applications of datalogging

\begin{tabular}{|c|c|c|}
\hline Themes & Categories & Codes \\
\hline \multirow[t]{2}{*}{$\begin{array}{l}\text { Different levels of datalogging } \\
\text { over time }\end{array}$} & Hearing aid trial & $\begin{array}{l}\text { The sound environment } \\
\text { Hearing aid operation } \\
\text { Hearing aid satisfaction } \\
\text { Use } \\
\text { Non-use } \\
\text { Comprehensive }\end{array}$ \\
\hline & $\begin{array}{l}\text { Ongoing / post hearing aid } \\
\text { trial }\end{array}$ & $\begin{array}{l}\text { Change of use } \\
\text { Change of sound environment } \\
\text { Hearing aid malfunction } \\
\text { Non-use }\end{array}$ \\
\hline \multirow[t]{3}{*}{$\begin{array}{l}\text { The dubious value of real-time } \\
\text { alerts }\end{array}$} & Valuable in specific context & $\begin{array}{l}\text { Notification for hearing aid } \\
\text { malfunction } \\
\text { Notification for hearing aid } \\
\text { non-use }\end{array}$ \\
\hline & Concern over misuse of alerts & $\begin{array}{l}\text { Clients abuse alerts } \\
\text { HCPs bombarded with client- } \\
\text { initiated alerts }\end{array}$ \\
\hline & Maintaining control & $\begin{array}{l}\text { Alert via email } \\
\text { Alert in fitting software } \\
\text { Check alert in own time } \\
\text { Similar process to current }\end{array}$ \\
\hline \multirow[t]{2}{*}{$\begin{array}{l}\text { Demonstrating hearing aid } \\
\text { value and supporting decision } \\
\text { making }\end{array}$} & Demonstrating value & $\begin{array}{l}\text { Justify cost } \\
\text { Increasing client knowledge } \\
\text { on hearing aid }\end{array}$ \\
\hline & $\begin{array}{l}\text { Recommending technology } \\
\text { based on datalogging }\end{array}$ & $\begin{array}{l}\text { Objectively demonstrate level } \\
\text { of technology } \\
\text { Justify better technology level } \\
\text { Justify lower technology level } \\
\text { Clients' needs }\end{array}$ \\
\hline
\end{tabular}




\section{HCP survey}

Demographic questions omitted, item added in version 2 are in italicized font

Today's hearing aids can log many aspects of hearing aid use, such as duration, type and sounds level of listening environment, what and when hearing aid adjustments are made, etc.

Do you look at data logging information?

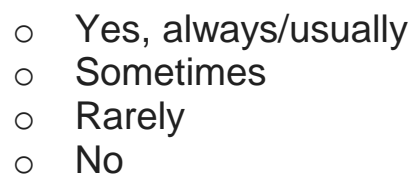

\section{QUESTION CONTINGENT ON ITEM ABOVE}

When you choose not to look at datalogging information, why is this? Check all that apply.

- I do not have the time to add this to my clinical care

- I am not sure how to make use of the data in my clinical care

- The information I can access is not clinically useful

- Other (specify):

When you look at datalogging information, how do you use it in your clinical process? Check all that apply.
- To monitor hearing aid usage
- To discuss information with the patient
- To adjust hearing aid settings
- Confirm patient reported usage
- Decide if patient needs a follow-up visit
- Other (specify)

When do you look at the datalogging information? Check all that apply.
- On a regular basis
- Prior to a follow-up visit
- During a follow-up visit
- Other (specify)

If you could have more detailed data logging information such as how and a patient adjusts his/her hearing aids, or graphs of minute by minute use in different listening environments, etc., would you be interested?
- Yes, I am interested in this
- Yes, but it is not practical for me
- Not sure
○ No 


\section{QUESTION CONTINGENT ON ITEM ABOVE}

You indicated that more data logging information is not practical/would not be of interest to you. Why is this the case? Check all that apply.

- I would not have the time to add this to my clinical care

- I am not sure how I would use the data in my clinical care

- I am not sure how I would access the data

- My clinic does not have a good enough computer system

- Other:

If you could provide your patients with an app that allows them to have detailed information about their own hearing aid use would you be interested?

- Yes, I am interested in this

- Yes, but it is not practical for me

- Not sure

$\circ$ No

\section{QUESTION CONTINGENT ON ITEM ABOVE}

You indicated that it is not practical/you would not want to provide your patients with an app. Why is this the case? Check all that apply.

- I would not have the time to add this to my clinical care

- My clinic does not have a good enough internet for me to help patient with this

- I do not think my patients would be interested

- I do not think my patients would be able to do this and/or they do not have

o the necessary equipment (smart cell phone etc.)

- I have tried it already and it was problematic

- Other (specify

If you have any additional comments to add please enter them here. 


\section{Structured interview guide}

We want to ask you some questions to do with tele-audiology. In particular, we want to know your thoughts about collecting data real time real world data from patients and their hearing aids - do you want this type of information? How might you use it? How would you like to receive it? Etc

What would you think if we told you that you could monitor your patients' hearing aid use, hearing aid settings, listening environments, subjective evaluations of listening and more?

Prompts: Would this information be helpful to you? How might you use the information? How would you like to receive the information? Is there any particular information you would like? Feel free to be creative. How often might you look at the information?

What would you think about getting this information during the 30-day trial period versus on an ongoing basis? Why?

Prompts: Is there a time point at which receiving input about a patient's hearing aids would no longer be of interest? When might that be? Why? Do you think the information you would like to see would change over time?

What kind of information would you like to know about a person's hearing aid use?

Prompts: Daily use, listening environments, program use, their opinions, nothing Why/Why not?

How would you use the information?

Prompts: For counseling patient, tracking business, learning for future, other, Tell me more...

How often would you like to receive information?

i. If it came from an automated system?

ii. If it came directly from patients?

Prompts: Real time, daily, when alert is triggered, on demand. Why/Why not?

In what form would you find the information most useful?

Prompts: Graphs, text, tables

What might you do with the information?

Prompts: Print it, add it to EHR, give it to patient, chart records, other?

It is possible to develop a system that automatically sends you a message say, if a patient stops using his/her hearing aid, or we could develop a system with which patients send you an alert only when they need assistance, or we could have system that has both possibilities. What would you think of this? Why? 
What kind of alerts might you want to receive?

Prompts: Low wear-time, low satisfaction, device performance issue

How might you use the alert?

Prompts: automated response, phone patient, add f/u appointment

What would you think about being able to customize alerts from patient to patient? E.g. alert type and thresholds for alerts

What do you think your patients would think about your collecting this type information? Why?

What would you think about being able to compare a particular patient's data with that of other data? For example, we could show you how much time each day/week/month a particular individual is using their hearing aids relative to other similar people. Why? What comparisons might be of interest?

Prompts: Similar age groups/similar hearing loss/other? Why?

Do you think your thoughts are likely to differ from those of your colleagues? Why?

Do you have any other ideas to share? Is there anything else you would like to let us know about this topic?

Prompts: What? Why? How? 